\title{
ESTÁGIOS IMATUROS DE LOXOLOMIA JOHNSONI SCHAUS (LEPIDOPTERA, SATURNIIDAE, ARSENURINAE)
}

\section{Eurides Furtado ${ }^{1}$}

\begin{abstract}
ImMature STAges of LOXolomia Johnsoni SCHAus (Lepidoptera, SATURNIDAE, ARSENURINAE). Data are presented on the life cycle and morphology of the immature stages of Loxolomia johnsoni Schaus, 1932. The larva feed on Cariniana legalis (Mart.) O. Ktze (Lecythidaceae).

KEY WORDS. Saturniidae, Arsenurinae, Loxolomia, host plants, immature stages
\end{abstract}

MAASSEN (1869) ao criar o gênero Loxolomia, descreveu L. serpentina, endemismo das regiões sudeste e sul do Brasil. Schaus (1932) descreveu $L$. johnsoni, baseado em um exemplar macho procedente de Chanchamayo, Peru (OiticiCA-FilHo 1957). LeMAIRE (1980), ao tratar esta última espécie, a considera um endemismo da região amazônica, com poucos exemplares conhecidos e pela primeira vez ilustra a fêmea. PEIGLER (1993) lamenta o desconhecimento dos estágios imaturos, e mesmo do primeiro ínstar, de três gêneros de Arsenurinae, incluindo Loxolomia.

Neste trabalho descreve-se pela primeira vez os estágios imaturos de uma espécie do gênero e divulga-se a planta hospedeira de ambas as espécies: Cariniana legalis (Mart.) O. Ktze (Lecythidaceae) para L. johnsoni e Cariniana sp. (Lecythidaceae) para $L$. serpentina.

O material estudado procede do Alto Rio Arinos, Diamantino, Mato Grosso, Brasil.

\section{RESULTADOS}

\section{Ovo (Fig. 1)}

Elipsóide, com dois lados achatados. Comprimento: $2,8 \mathrm{~mm}$; largura: 2,0 $\mathrm{mm}$; espessura: $1,2 \mathrm{~mm}$. Coloração: face maior castanho-escura com mancha central branca, irregular; face menor branca com as bordas e um dos lados ferrugíneos e parcialmente invadida com a coloração da face maior; o outro lado com maior área branca e com micropila preta. Período embrionário: seis a sete dias.

\section{Larva}

Primeiro ínstar (Fig. 2). Cabeça cordiforme, lisa, castanho-clara translúcida, com cerdas esparsas esbranquiçadas; peças bucais e ocelos mais escuros. Pernas torácicas, abdominais e anais castanho-avermelhadas translúcidas.

Três séries de pequenos scoli espiniformes assim distribuídos: supra-espiracular, mais curtos que os demais; sub- e dorsais maiores, com a haste eriçada de minúsculos espinhos. Protórax com dois scoli sub-dorsais com ápice arredondado

1) Caixa Postal $97,78400-000$ Diamantino, Mato Grosso, Brasil. 
provido de cerda espiniforme preta, e pouco abaixo, uma protuberância aguda com cerda espiniforme na ponta, vermelhos, área mediana anelada de amarelo. Metatórax com dois longos scoli, bífidos, maiores o triplo dos anteriores, curvados na parte mediana e apical para trás, com cerda preta nas pontas, vermelhos com a porção mediana anelada de amarelo. Segmento A8 corcovado, scolus dorsal com tamanho aproximado de $1 / 3$ dos metatorácicos, bífido, cerda preta nos ápices, porção mediana anelada de amarelo com pouco destaque. Tegumento pubescente, vermelho escuro, pouco mais claro na área ventral; áreas lateral e dorsal matizadas de amarelo, entremeadas com vermelho-escuro. Cerdas esbranquiçadas sub-espiraculares em todos segmentos e no dorso da placa supranal. Os scoli sub-dorsais pro- e metatorácicos são duplos e com pequena verruga na base. Comprimento da larva ao eclodir: 6,5 mm; no final do ínstar: $10 \mathrm{~mm}$. Duração: quatro dias.

Segundo ínstar (Fig. 3). Cabeça com o mesmo formato anterior, coriácea, verde-oliva clara, sutura epicranial mais escura; frontoclípeo castanho; ocelos e base das antenas mais escuros. Dois scoli protorácicos fundidos, projetados para a frente, de formato piramidal; em cada lado da base, pequena protuberância ocrácea eriçada de espinhos e em seguida todos os lados cobertos com espinhos ocráceos até o ápice, este mais rugoso, castanho-escuro com os espinhos pouco maiores que os anteriores; a coloração é amarelo-citrina no pronoto, da faixa espiracular à base dos scoli e gradativamente castanho-amarelada daí à área apical. Metatórax corcovado; dois scoli dorsais, projetados para a lateral e gradativamente curvados para trás; mais grossos na base e gradativamente mais finos no ápice, este levemente bífido e achatado com toda a extensão eriçada de minúsculos espinhos; ocráceos com anelações amarelo-citrinas nas áreas pós-basal e pós-mediana. O scolus de A8 tem o tamanho aproximado dos protorácicos, grosso na base e mais fino à medida que avança para o ápice, haste rugosa com protuberâncias espinhosas; ocráceo com invasões amarelo-citrinas pós-basal e pós-mediana. Pernas torácicas ocráceas; abdominais e anais ocre-avermelhadas nos escudos laterais, o restante com a mesma cor do tegumento. Dorso de A8 à placa supranal com a linha dorsal ocrácea a partir da base do scolus. Tegumento verde; linha mediana ventral larga, esbranquiçada; linha dorsal de A3-5 ferrugínea, mais larga em A4; amarelo-citrino da área sub à dorsal do metatórax e A3-5, dorsal de A8 na base do scolus e região anal; linhas ou estreitas faixas amarelo-citrinas assim distribuídas: sub-dorsal nos segmentos torácicos, oblíquas nos segmentos abdominais, partindo do dorso à sub-espiracular. Faixa espiracular amarelo-citrina, sendo sub-espiracular em T1 e A1. Espiráculos pouco visíveis, castanho-claros, com mais destaque em T1. Comprimento: $14 \mathrm{~mm}$. Duração: quatro dias.

Terceiro ínstar (Fig. 4). Difere do ínstar anterior como segue: ápice dos scoli metatorácicos afilado, agudo; haste verde-amarelada, com manchas ocráceas na base e castanho-escuras na face ventral; a coloração ferrugínea em A4 se divide em três manchas arredondadas, pontilhadas com tom mais escuro, uma em cada lado na área sub-dorsal, menores, e uma maior na linha dorsal; a linha oblíqua em A8 é mais larga que as demais, desde seu início na base do scolus. Em repouso a larva mantém os scoli metatorácicos deitados sobre o abdome, na área sub-dorsal. Comprimento: $23 \mathrm{~mm}$. Duração: cinco dias. 

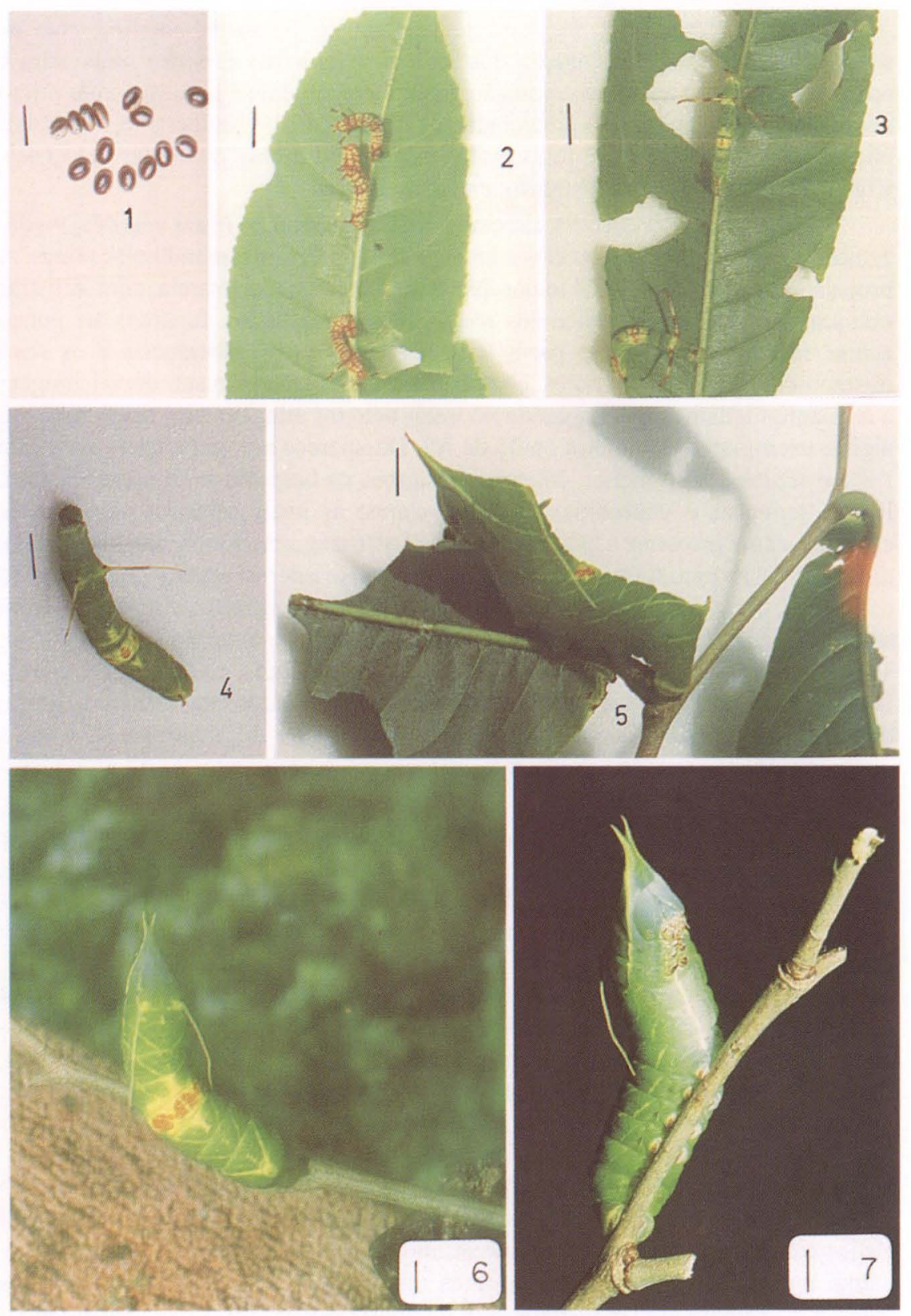

Figs 1-7. Ovos e larvas de Loxolomia johnsoni. (1) Ovos; (2) primeiro instar, vista dorsal; (3) segundo instar, vista dorsal; (4) terceiro ínstar, vista dorsal; (5) quarto instar, vista lateral sobre a planta hospedeira; (6) quinto instar, vista dorsal; (7) quinto instar, vista lateroventral. 
Quarto ínstar (Fig. 5). Aspecto geral como no ínstar anterior, com as seguintes diferenças: a coloração dos scoli metatorácicos é pouco mais clara e amarelada no terço apical; a coloração verde do tegumento é matizada com micro pontuações castanho-claras e amareladas; o protórax é mais protuberante, triangular, encimado pelos scoli; A8 é mais protuberante, com a base do scolus verrugosa. Comprimento: 30-32 mm. Duração: cinco a seis dias.

Quinto ínstar (Figs 6-7). Formato da cabeça como no ínstar anterior; verdeazulada, com frontoclípeo, ocelos e antenas castanho-claros; mandíbulas pretas. A projeção dorsal do protórax é maior que antes, lateralmente amarela, com as listras oblíquas até próximo ao ápice dos scoli, estes acastanhados, fundidos até pouco acima da área mediana e a partir daí separados. As protuberâncias e os scoli metatorácicos são bem menores, estes dobrados sobre a região sub-dorsal atingem a área ante-mediana de $\mathrm{A} 3$, quando no ínstar anterior atingem totalmente $\mathrm{A} 6 \mathrm{e} \mathrm{em}$ alguns exemplares o primeiro ânulo de A7. Desaparece a protuberância dorsal de A8 e o scolus é bem menor. Mancha ferrugínea na base dos scoli metatorácicos. Pernas torácicas e abdominais castanho-claras; as anais amarelas seguidas de castanho-claro próximo à planta. Escudo anal triangular. Linha dorsal amarela, grossa de A8 ao escudo anal. As manchas em A4 são: a dorsal é maior quase o dobro das outras, trapezoidal, com fundo amarelo e pontos ferrugíneos, circundados com amarelo; as sub-dorsais arredondadas com pontuações e amarelo como a dorsal. Tegumento verde- azulado com pontuação mais marcada na área ventral; verde-azulado no dorso de T1-2; o restante verde-folha com pontuação fina castanho-escura, com manchas amarelas dorsais nas áreas limite entre $\mathrm{T} 3 \mathrm{e} \mathrm{A} 1$, maior em $\mathrm{A} 3$ e ainda maior em A5. Espiráculos elipsoidais, castanhos. Comprimento: 37-43 mm. Duração: cinco a sete dias.

Sexto ínstar (Figs 8-9). Cabeça arredondada, verde-oliva claro; fronte e clípeo castanho-claro esbranquiçados, ocelos mais escuros, mandíbulas pretas; antenas grossas, verdes na metade basal, castanho-claras na distal. Protórax projetado para a frente, triangular, semelhante ao ínstar anterior mas sem os scoli quitinosos. Metatórax com apenas vestígios das corcovas, quase lisos, sem scoli. A8 também sem scolus; dorso com leve vestígio da corcova. Placa supranal hastiforme, verde-amarelada com pontuação e linha dorsal amarelas. Pernas torácicas castanho-claras na borda externa e castanhas na interna; as abdominais verdes, seguida de coloração amarelada e orla castanho-escura com cerdas esbranquiçadas, planta castanho-clara com cerdas da mesma cor; pernas anais verdes; escudo triangular pontilhado de amarelo na porção posterior. Espiráculos elipsoidais, amarelados; peritrema ferrugíneo. Manchas dorsais, ambas com o mesmo tamanho e forma trapezoidal; as sub-dorsais com coloração de fundo amarelo-citrina mescladas com ferrugíneo e pontuação castanho-escura, quase preta; a dorsal é levemente mesclada em ambos os lados da linha dorsal, com pontuação como as anteriores. Tegumento verde-folha com marmorizações puntiformes castanho-claras, matizadas com verde-azulado na dorsal de T2 e parte de T1 e T3, supra espiracular de A4-5, sub-dorsal de A6 e área abdominal de A1-4. Linha dorsal amarela, larga, do metatórax à placa supranal. Linhas obliquas amarelas assim distribuídas: a primeira vai da sub-dorsal de T3 à mesma área de T1; as demais, em 

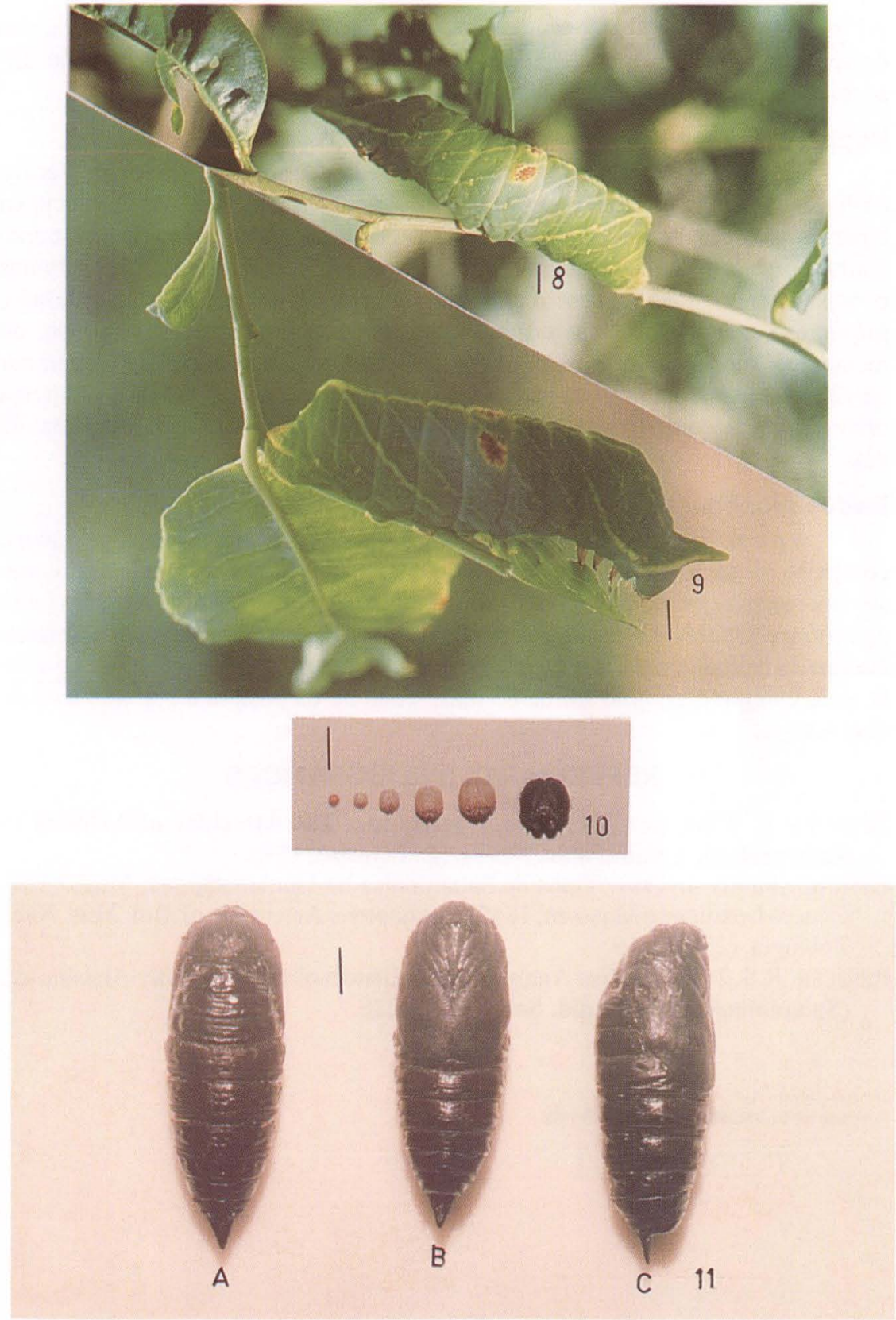

Figs 8-11. (8-9) Larvas de sexto instar, vista lateral; (10) vista frontal das cápsulas cefálicas dos seis instares; (11) pupa: (A) vista dorsal, $(B)$ vista ventral, $(C)$ vista lateral. Escala $=5 \mathrm{~mm}$. 
A1-8, iniciam-se na linha dorsal de cada segmento e terminam na área espiracular do segmento anterior, a de A2 funde-se com a faixa amarela sub-espiracular dos segmentos torácicos. Comprimento: $54-58 \mathrm{~mm}$. Duração: sete a dez dias.

Pupa (Fig. 11 a,b,c)

Tegumento liso, castanho-escuro, levemente avermelhado de A5 a 8 . Vértice e adjacências com rugosidades suaves, puntiformes nos olhos. Antenas, frontoclípeo e pernas salientes; rugosidade fina. Pronoto com duas concavidades laterais, trapezoidais, pretas, mais longas no sentido dorso ventral. Estojo das asas liso, nervuras pouco aparentes; duas pequenas calosidades agudas sub-dorsais, uma em cada lado, próximo à sutura. Dois sulcos sub-dorsais arredondados, um em cada lado, no metanoto. Calosidades na área ventral de A5-6; concavidade em A9-10. Cremaster hastiforme. Espiráculos elipsoidais, irregulares; área periférica saliente, peritrema preto. Comprimento: $40 \mathrm{~mm}$. Maior largura: $14 \mathrm{~mm}$; menor: $13 \mathrm{~mm}$. Diapausa: 49 dias.

\section{Dados bionômicos}

A partir do segundo ínstar e sobretudo nos últimos, a larva tem sua principal coloração idêntica às folhas da planta nutridora. Sua forma característica de repousar, apoiada nas pernas abdominais, com a cabeça e pernas torácicas retraídas junto ao ventre, constitui uma perfeita camuflagem. Larvas solitárias em todos os ínstares. No fim do último ínstar a larva tem a coloração geral esmaecida e oculta-se no solo. O ciclo evolutivo mínimo foi de 85 dias, sendo 36 da postura à pupação e 49 de diapausa.

\section{REFERÊNCIAS BIBLIOGRÁFICAS}

Lemaire, C. 1980. Les Attacidae Américains... The Attacidae of America (= Saturniidae), Arsenurinae. Nevilly, C. Lemaire, 199p.

Oiticica-Filho, J. 1957. Tipos de Saturnioidea no United National Museum 8 Gênero Loxolomia Maassen, 1869 (Lepidoptera, Arsenurinae). Bol. Mus. Nac., Zoologia, (156): 1-15.

Peigler, R.S. 1993. Cladisc Analysis of the Genera of the Subfamily Arsenurinae (Saturniidae). Jour. Lepid. Soc. 47: 211-228.

Recebido em 01.VIII. 1997; aceito em 01.X. 1998. 